\title{
Reading Comprehension and Eye-Tracking in College Students: Comparison between Low- and Middle-Skilled Readers
}

\author{
Alicia Abundis-Gutiérrez ${ }^{1,2}$, Víctor Hugo González-Becerra ${ }^{1 *}$, Jahaziel Molina del Río ${ }^{1,3}$, \\ Mónica Almeida López ${ }^{4}$, Anaid Amira Villegas Ramírez¹, Diana Ortiz Sánchez¹, \\ José Rodolfo Alcázar Huerta ${ }^{4}$, Luis Alfonso Zepeda Capilla ${ }^{4}$ \\ ${ }^{1}$ Behavior and Health Research Center, University of Guadalajara-Valley's University Center, Jalisco, México \\ ${ }^{2}$ Laboratory of Human Behavior and Cognition, University of Guadalajara-Valley's University Center, Jalisco, México \\ ${ }^{3}$ Laboratory of Neuropsychology, University of Guadalajara-Valley’s University Center, Jalisco, México \\ ${ }^{4}$ University of Guadalajara, Jalisco, México \\ Email: *victor.becerra@profesores.valles.udg.mx
}

How to cite this paper: Abundis-Gutiérrez, A., González-Becerra, V. H., del Río, J. M., López, M. A., Ramírez, A. A. V., Sánchez, D. O., Huerta, J. R. A., \& Capilla, L. A. Z. (2018). Reading Comprehension and Eye-Tracking in College Students: Comparison between Low- and Middle-Skilled Readers. Psychology, 9, 2972-2983.

https://doi.org/10.4236/psych.2018.915172

Received: November 20, 2018

Accepted: December 22, 2018

Published: December 25, 2018

Copyright $\odot 2018$ by authors and Scientific Research Publishing Inc.

This work is licensed under the Creative

Commons Attribution International

License (CC BY 4.0).

http://creativecommons.org/licenses/by/4.0/

\begin{abstract}
Efficient reading begins with text decoding and finish with comprehension. When there is a lack of reading comprehension (RC), the person is likely unable to use the main information of a text in everyday life; something related to non-functional literacy. Using eye-tracking technique, some researchers have found that regressions (return to previously read text) are a common behavior during reading, and sometimes they are used as a rereading strategy to improve RC. However, the utility of regressions to improve RC depends on the reader's skills. Based on these data, the main purpose of this study was to compare regressions and RC between low- and middle-skilled readers. Eighteen college students completed a computerized version of a middle school student's RC test (ECOMPLEC-Sec) while their eye movements were recorded. We found a statistically marginal relation between regressions during narrative text and text-based RC on low-skilled readers. However, our results indicated no relation between number of regressions and RC regardless of level of reading competency. The necessity of new research to increase the knowledge of RC using eye-tracking parameters was discussed.
\end{abstract}

\section{Keywords}

Eye-Tracking, Reading Comprehension, Regressions, Literacy, Educational Psychology

\section{Introduction}

When someone read without comprehension (s)he could be unable to use the 
main information of a text in her/his own life, something related to non-functional literacy. Illiteracy was one of the biggest world educational challenges some decades ago, however, nowadays functional literacy is one of the main subjects in industrialized countries (UNESCO, 2005). In this regard, México is still facing both problems: in 2010, six million of the Mexican population were illiterate (Narro \& Moctezuma, 2012) and in 2015, more than 50\% of 15 years students showed a low performance in RC, mathematics and science skills in the Program for International Student Assessment (PISA) (INEE, 2017). Concerning reading comprehension (RC), the National Institute of Education Assessment (INEE, initials in Spanish) found that more than $60 \%$ of the students in last grade of elementary and middle school achieved a level related to poor RC performance (INEE, 2016). A similar problem is found in many countries around the world, even in countries with high level of economy and culture (OECD, 2015).

There are different analytical alternatives in the study of reading that could involve both simple and complex parameters in the assessment process (e.g., Adams \& Wu, 2003; Kintsch \& van Dijk, 1978; León, Escudero, \& Olmos, 2012; Rayner, 1990; Ribes, Ibáñez, \& Pérez, 2014). From an overall outlook, reading development begins with text decoding skills and finish with comprehension. Concerning RC, almost all the analytical alternatives claim that the complexity of readers' skills improves from textual (literal) to inferential, as shown by readers' accuracy to answer questions about text content. The simplest skill of RC is textual comprehension, shown when a reader is able to retrieve explicit information from a text, for instance, answering how many dwarfs are in Snow White Tale. In the other hand, a reader shows inferential comprehension when (s)he finds some implicit link between the information given in various sites of the text either by analogy, syllogism, relation cause-effect and any other cognitive skill that support it (León, Escudero, \& Olmos, 2012; OECD, 2015).

Narrative texts are the most used reading material format to teach decoding and RC at schools. Therefore, it is to be expected that students of different educational level showed better performance in narrative comprehension than other type of texts (Best, Floyd, \& Mcnamara, 2008; Fuentes, 2009; González-Becerra, García, Almeida, Navarro, Molina, \& Ramos, 2015; Sáenz \& Fuchs, 2002). Nonetheless, it is necessary that children and youth are able to comprehend other sources of information, like continuous texts with other literary styles (i.e., expository, argumentative) and non-continuous texts (i.e., lists, forms, graphs, diagrams) (OECD, 2001).

Before eye-tracking technology, researchers ignored that some eye-movement behavior during reading are related to text decoding and comprehending. For instance, readers go back (his) her gaze during reading about $10 \%$ to $15 \%$ of the time (regressions) and their average of fixation time in a word and saccade length vary in relation to words functions (i.e., novelty, familiarity, oddity, ambiguity, relevancy) (Rayner, 1993). Concerning these parameters of eye-movement, readers are classified as: 1) proactive (long saccades, many regressions), and 2) 
conservative (short saccades, few regressions); the reading strategies used by both are related to low or high level of reading experience, respectively (Koornneef \& Mulders, 2017; Vorstius, Radach, \& Lonigan, 2014).

Booth and Weger (2013) conducted three experiments with university students to find evidence about the role of regressions during reading. In each experiment, RC and eye movement were evaluated while students read sentences presented in different tasks. After the students read or heard a sentence, this one remained, disappeared and/or was replaced by other stimuli (i.e., points, letters, words with other meanings). The regressions to the remaining sentence were related to a strategy of rereading; moreover, when the regression was to a substituted sentence it was assumed that students used a deictic strategy (improvement of memory by word location). Results showed that rereading strategy related to RC, suggesting that readers made regressions when they needed information to improve their comprehension. Instead, regressions to word locations in substituted sentences did not improve comprehension; opposite evidence to the assumptions of deictic strategy. However, RC was higher when students did not make regressions. Apparently, regressions help to improve RC, but they are not a necessary condition (Barnes \& Kim, 2016; Koornneef \& Mulders, 2017; Vorstius, Radach, \& Lonigan, 2014).

Most of the eye-tracking research on reading is focused on textual (literal) comprehension, and it is usually evaluated by reading sentences (Barnes \& Kim, 2016; Booth \& Weger, 2013; Rayner, 1993; Vorstius, Radach, \& Lonigan, 2014). On the other hand, long texts (i.e., tales, scientific reports) and inferential questions are also used for the study of RC (Koornneef \& Mulders, 2017). But proactive readers show higher RC than conservative readers despite the text's length (short or long) and the question's complexity (literal/textual or inferential).

Regarding that, Krstić, Šoškić, Ković, \& Holmqvist (2018) conducted a study to evaluate RC with PISA test, and also the eye-movement during reading in 15 -year-old students with low and high reading skills. Scores in reading speed (words read per minute; WPM) and RC were used to classify reading skills. The students read continuous and noncontinuous texts that were available while questions (textual and inferential) appeared on a screen. These authors found that students with high reading skills performed better than students with low skills in textual and inferential comprehension questions, on both continuous and non-continuous texts. Saccade amplitude (length) and percentage of regressions were higher in students with high reading skills, as found in other studies (Koornneef \& Mulders, 2017). Difference between groups concerning their eye-movement patterns increased in relation to complexity of questions, from textual to inferential comprehension. Besides, readers with low skills showed more variability in eye-movement because they tracked the whole text instead of the parts with relevant information.

As mentioned before, most of the studies in this field record eye movement during single sentence presentation. The main purpose of the present study was to compare regressions and RC between low- and middle-skilled readers during 
non-stop text reading, as well as the association between these two measures. Readers' skills were determined by RC assessment based on PISA (León, Escudero, \& Olmos, 2012).

\section{Method}

\subsection{Participants}

Eighteen college students participated in the present study (4 males, mean age $=$ 20.9 years, $\mathrm{SD}=1.7$ years). Participants were volunteers and received no compensation to participate. All students came from a University Campus within a rural area. The participants were assigned to two groups according to their level of RC, namely: low-RC (LRC) and Middle-RC (MRC) group.

\subsection{Task}

To assess RC participants completed a computerized version of the ECOMPLEC-Sec test (León, Escudero, \& Olmos, 2012). The ECOMPLEC-Sec was designed for middle school students (aged 13 - 15-years), it includes three types of text: narrative (leisure reading), expository (acquisition of scientific of academic knowledge), and discontinuous (search for graphic information). After reading each text, participants completed a multiple-choice questionnaire concerning the content of the text previously read, and two metacognitive questions about the perceived difficulty of the text and the questionnaire. The narrative text is by Julio Cortázar (1956), "Continuidad de los parques" ("Continuity of Parks") (541 words, 27 questions); the expository text, "Los árboles estranguladores" ("Strangler trees") (500 words, 25 questions), taken from an academic textbook, and the discontinuous text, "Ocio" ("Leisure"), is a text with graphs and figures regarding the young Spaniards' leisure habits (22 questions).

In order to guarantee a good quality eye movement registration during reading, the texts of the ECOMPLEC-Sec were segmented into various presentations consisted in three text lines (calibri font size 35 , line spacing of $3 \mathrm{~cm}$.) written in white font on a black background in a 15 inches laptop screen. After reading each segment, participants were instructed to press a key to pass to the next segment in order to continue reading until they finished the text. During questionnaire completion, the whole text was available to participants: questions appeared, one by one, at the left side of the screen and the text was at the right side. Participants reported their answers on a paper format. ECOMPLEC-Sec completion took approximately 20 minutes per participant.

As far as we know, there is no a standardized test for Mexican population in Spanish to appraise RC in adults. Previous studies (unpublished), using the ECOMPLEC-Sec, have shown that the same population of our sample have low RC, despite being assessed by a test intended for 13 - 15-year-olds. Based on these results, we consider the ECOMPLEC-Sec could be a suitable instrument to evaluate $\mathrm{RC}$ on rural college students. 


\subsection{Procedure}

Participants completed the ECOMPLEC-Sec in the Research Center for Behavior and Health of the University of Guadalajara. Participants were seated at approximately $60 \mathrm{~cm}$ from a laptop, and approximately $50 \mathrm{~cm}$ from a Gazepoint GP3 eye tracker $\left(60 \mathrm{~Hz}\right.$ sampling rate; accuracy between 0.5 and $\left.1^{\circ}\right)$. Luminance, temperature and noise kept similar in all experimental sessions. Experimenter explained the task and the importance to keep the posture and distance towards the screen in order to properly register eye movements. Experimenter was present throughout the session to visually inspect participants' eye movement recording in a separate screen; if needed, experimenter requested participants to adjusts their posture until their eyes were captured by the eye tracker again. All participants completed a 9-point calibration phase using Gaze-point calibration system. Participants were instructed to carefully read each of the three texts and answer to the questions following. Presentation of the texts was in the following order: narrative, expository and discontinuous.

\section{Results}

Two participants were excluded from the analysis due to a difference of 2 standard deviations from the sample mean in the Global Comprehension Index.

\subsection{Performance Measures}

ECOMPLEC-Sec provides different scores that reflect both global and specific aspects of RC. The global reading comprehension (RC-Global) indicates general reading competency, but it gives no information regarding specific abilities or difficulties during RC. ECOMPLEC-Sec uses a typical score based on a mean of 50 and SD of 20. The results reported in this study are the typical scores, based on percentiles. Participants with Low-Reading-Comprehension (LRC) obtained a mean RC-Global of 24.87 (SD 3.27) and Middle-Reading-Comprehension (MRC) participants obtained 41.87 (SD 6.87). According to ECOMPLEC-Sec qualitative ranges, these scores indicate a low-medium and a medium reading competency for LRC and MRC groups, respectively. It is necessary to detach that participants reading performance were compared to middle school students, which suggests that the skills required to fully comprehend narrative, expository and discontinuous texts are not fully developed in our sample. This is also reflected in the scores obtained in narrative (mean $=32.00, \mathrm{SD}=12.45$ for LCR-group; mean $=46.75, \mathrm{SD}=10.63$ for MCR-group) and expository (mean = 34.37, $\mathrm{SD}=12.02$ for LCR-group; mean $=43.87, \mathrm{SD}=11.90$ for MCR-group) texts, which are also within a middle school medium-low range. All RC comparisons between LRC and MRC groups were statistically significant (see Figure 1 and Table 1).

Regarding the level of representation, MRC and LRC groups showed a significant difference between the RC Inferential and RC Textual ( $t$-test, $p<0.05)$. The RC Inferential score reflects mental representation skills, as well as the skill 


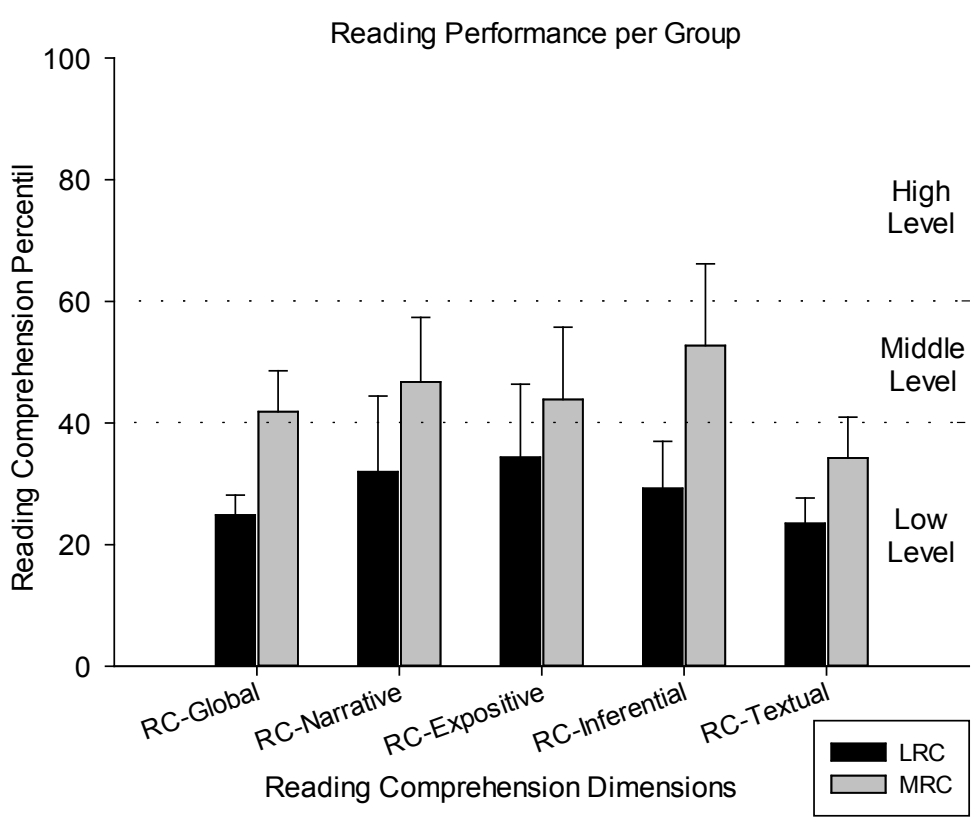

Figure 1. Reading Comprehension of college students using the yardstick for students of 5th grade of middle school. Note: $\mathrm{RC}=$ Reading Comprehension, LRC = Low Reading Comprehension Group, MRC = Middle Reading Comprehension Group.

Table 1. Statistical differences of LCR-Group and MCR-Group of percentiles of Reading Comprehension and frequency of regressions during reading.

\begin{tabular}{ccccccc}
\hline & \multicolumn{7}{c}{ LRC } & \multicolumn{2}{c}{ MRC } & & \\
\cline { 2 - 7 } & Mean & SD & Mean & SD & $\boldsymbol{t}$ & $\boldsymbol{p}$ \\
\hline Global Comprehension index & 24.87 & 3.27 & 41.87 & 6.87 & -6.31 & 0.000 \\
RC Narrative & 32.00 & 12.45 & 46.75 & 10.63 & -2.54 & 0.023 \\
RC Expository & 34.37 & 12.02 & 43.87 & 11.90 & -1.58 & 0.135 \\
RC Inferential & 29.25 & 7.75 & 52.75 & 13.43 & -4.28 & 0.001 \\
RC Textual & 23.50 & 4.17 & 34.25 & 6.73 & -3.83 & 0.002 \\
Narrative Regressions & 33.37 & 16.36 & 52.50 & 26.20 & -1.75 & 0.102 \\
Expository Regressions & 30.00 & 14.36 & 43.50 & 14.36 & -1.88 & 0.081 \\
\hline
\end{tabular}

Note: $\mathrm{RC}=$ Reading Comprehension, $\mathrm{LRC}=$ Low Reading Comprehension Group, MRC $=$ Middle Reading Comprehension Group.

to make inferences based on previous knowledge, and effectively integrate the new information into previous knowledge system. On the other hand, RC Textual reflects the level of representation based on the text, which implies the use of explicit information. Low range of this level of representation suggests a difficulty in the reproduction of explicit information and lack of knowledge that obstruct semantic connections, causal connections and the use of information to formulate and support arguments (León, Escudero, \& Olmos, 2012). It is impor- 
tant to note that a low scoring could also indicate a lack of interest or motivation. Differences between inferential and textual RC on narrative text were marginally significant ( $t$ test, $p<0.09$ ), and no difference was found on expository text (see Figure 1 and Table 1).

LRC group obtained a low-medium range score in both narrative (mean $=32$, $\mathrm{SD}=12.45)$ and expository $($ mean $=34.37, \mathrm{SD}=12.02)$ texts. For level of representation, LRC obtained a low range on both $\mathrm{RC}$ Inferential (mean $=29.25, \mathrm{SD}=$ 7.75 ) and $\mathrm{RC}$ textual (mean $=23.50, \mathrm{SD}=4.17$ ). Besides, they showed similar reading performance on narrative text about $\mathrm{RC}$ Inferential (mean $=36.5, \mathrm{SD}=$ 17 ) and RC textual (mean $=33, \mathrm{SD}=10$ ), as well as for expository RC Inferential (mean $=37.6, \mathrm{SD}=15.7)$ and $\mathrm{RC}$ textual (mean $=35.2, \mathrm{SD}=12.7)$ scores. On the other hand, MRC group obtained a medium range score on both narrative (mean $=46.7, \mathrm{SD}=10.6)$ and expository (mean $=43.9, \mathrm{SD}=12)$ texts, as well as on the RC Inferential (mean $=52.7, \mathrm{SD}=13.4$ ) level of representation, and medium-low range on $\mathrm{RC}$ textual (mean $=34.2, \mathrm{SD}=6.7$ ) level of representation.

$\mathrm{MRC}$ showed a medium range for narrative $\mathrm{RC}$ Inferential (mean $=54.5, \mathrm{SD}=$ 10.7) and medium-low for narrative $\mathrm{RC}$ textual (mean $=41, \mathrm{SD}=14.2$ ), as well as for expositive RC Inferential (mean $=41.6, \mathrm{SD}=15.4$ ) and $\mathrm{RC}$ textual (mean $=48.5, \mathrm{SD}=16.1)$ scores. Differences between global inferential and textual RC scores were found ( $t=3.570 ; p<0.01$ ), as well as a difference between narrative inferential and textual RC scores $(t=2.433 ; p<0.05)$.

\subsection{Eye tracking Metrics: Number of Regressions}

Regarding eye regression during reading, we found a mean of 39.5 (SD =17.3) of total regressions made during narrative (mean $=42.9, \mathrm{SD}=23.3$ ) and expository (mean $=36.7, \mathrm{SD}=15.5)$ texts reading. No differences were found between text type $(t=-1.613 ; p>0.05)$.

LRC group made a total of $33.5(\mathrm{SD}=15)$ regressions during narrative (mean $=$ $33.4, \mathrm{SD}=16.4)$ and expository $($ mean $=30, \mathrm{SD}=14.4)$ texts reading. MRC group made a total of $45.5(\mathrm{SD}=18.2)$ regressions during narrative (mean = $52.5, \mathrm{SD}=26.2)$ and expository $($ mean $=43.5, \mathrm{SD}=14.4)$ texts reading. Marginal difference in number of regressions during expositive text reading were found between groups $(t=-1.880 ; p=0.081)$ (see Table 2 and Figure 2).

No correlations were found between number of regressions made and ECOMPLEC-Sec scores. Only a marginal correlation on the LRC group between $\mathrm{RC}$ Textual and regressions during narrative text was found ( $\mathrm{r} 2=0.67 ; p=0.07)$.

\section{Discussion}

The main purpose of the study was to compare reading performance between students with low reading comprehension (LRC) and middle reading comprehension (MRC). Reading comprehension (RC) level shown by both groups of college students were low, and this fact is worthy of consideration because they were assessed with an instrument designed for middle school students in their 
Table 2. Correlations of reading comprehension dimensions and types of regressions.

\begin{tabular}{ccccccc}
\hline & \multicolumn{2}{c}{ RC Global } & \multicolumn{2}{c}{ Narrative Regression } & \multicolumn{2}{c}{ Expository Regression } \\
\cline { 2 - 7 } & LRC & MRC & LRC & MRC & LRC & MRC \\
\hline RC Global & & & -0.333 & -0.100 & -0.481 & -0.205 \\
RC Narrative & $0.726^{*}$ & 0.377 & -0.032 & 0.006 & -0.272 & 0.074 \\
RC Expository & 0.245 & $0.649 \sim$ & -0.342 & 0.338 & -0.538 & 0.198 \\
RC Inferential & $0.654 \sim$ & $0.839^{* *}$ & -0.562 & -0.013 & -0.337 & -0.167 \\
RC Textual & 0.371 & 0.556 & $0.668 \sim$ & 0.074 & 0.438 & 0.105 \\
RC Narrative Inferential & 0.592 & 0.308 & 0.124 & -0.465 & 0.023 & -0.032 \\
RC Narrative Textual & 0.438 & 0.268 & -0.219 & 0.319 & -0.487 & 0.127 \\
RC Expository Inferential & 0.144 & 0.232 & -0.519 & 0.571 & -0.574 & -0.057 \\
RC Expository Textual & 0.241 & $0.646 \sim$ & 0.142 & -0.021 & -0.119 & 0.361 \\
\hline
\end{tabular}

Note 1: RC = Reading Comprehension, LRC = Low Reading Comprehension Group, MRC = Middle Read ing Comprehension Group. Note 2: Marginal correlation at level 0.099; ${ }^{\star}$ Significant correlation at level $0.05 ;{ }^{*}$ Significant correlation at level 0.01 .

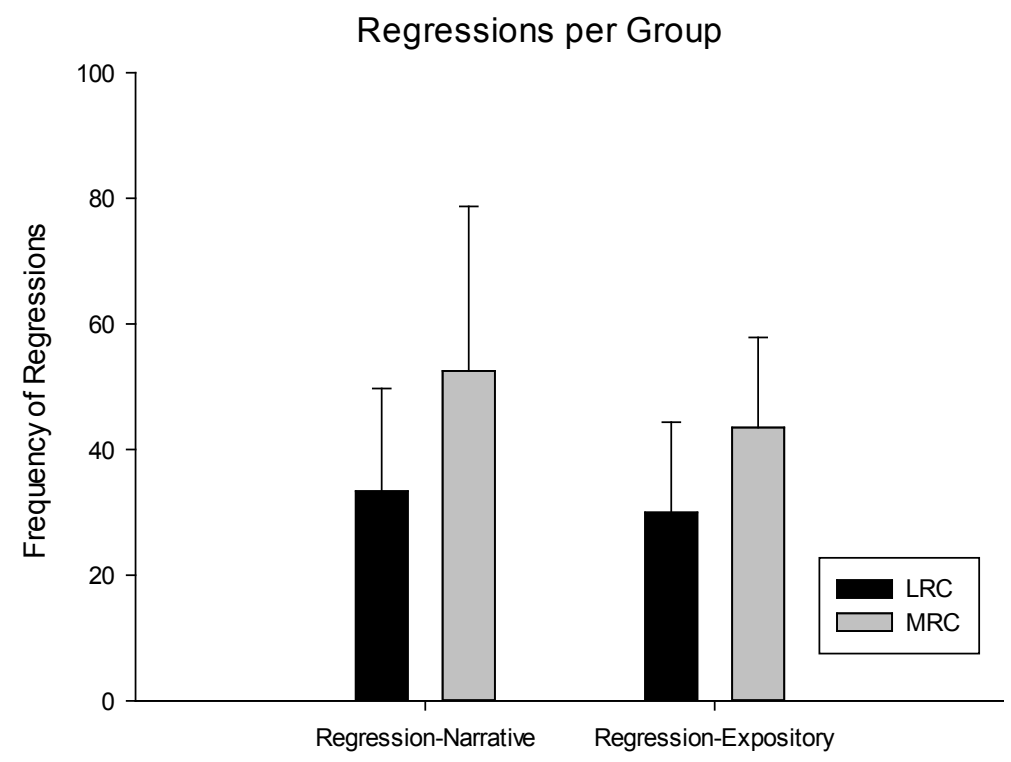

Figure 2. Frequency of regressions during reading per group in narrative and expository texts. Note: LRC = Low Reading Comprehension Group, MRC $=$ Middle Reading Comprehension Group.

$3^{\text {rd }}$ grade. Significant differences between groups on Global RC, narrative RC, and levels of representation were found. However, no relation between RC and regression was found, regardless of level of RC competency.

Unfortunately, LRC on rural students of elementary and middle school, in comparison to urban students, is a consequence of sociocultural disadvantages (e.g., Backoff, 2009; Canales, 2012; Canales et al., 2014; González-Becerra et al., 2015), something that seems to persist until university. The college students with 
LRC and MRC of this study showed similar patterns of regressions as observed on conservative and proactive readers, respectively (Booth \& Weger, 2013; Koornneef \& Mulders, 2017; Krstić, Šoškić, Ković, \& Holmqvist, 2018).

Comprehension of narrative text requires different modalities of knowledge: conceptual, empathic, goal oriented, and metacognitive, whereas, explicative text comprehension demands conceptual, technical/scientific, and episodic knowledge (León et al., 2012). Low scoring is not necessary a lack of knowledge, rather the inability to manage the previous knowledge.

The first highlight in this study was that regressions and $\mathrm{RC}$ do not correlate, despite the significant difference on RC found between LRC and MRC groups, and the evidence in the literature that better readers made more regressions. However, in some studies, regressions frequency did not correlate with RC; instead there were found other eye-tracking parameters that correlate with RC: regressions to specific words, time of fixations during regressions and regressions patterns (e.g., Barnes \& Kim, 2016; Inhoff, Weger, \& Radach, 2005; Krstić, Šoškić, Ković, \& Holmqvist, 2018). Additionally, there is evidence related to a negative correlation between regressions and $\mathrm{RC}$, attributed to readers who did not need reread the text because they comprehended it with only one gaze (Booth \& Weger, 2013; Hyönä \& Olson 1995; Vorstius, Radach, \& Lonigan, 2014).

Our results suggest that regressions have different functions and they may change in relation to different variables. For instance, regressions could be used as a tool to improve RC for readers with high reading skills or it could be related to low RC when readers with low reading skills make many regressions without success. The regression's functions change regarding the skills of the reader. About that, MRC group showed more regressions and more RC, in this case regressions could have been used as a strategy to improve RC. On the other hand, the function of regressions was different in LRC group because it did not help to improve RC; instead it might be considered a sign of confusion. In this regard, the negative correlations between regressions and RC (more regressions, less RC) showed by LRC group in some RC dimensions could be related to confusion, although these correlations were not significant. On the other hand, there was only one marginal correlation, showed by LRC group, between RC textual and regressions in narrative text, evidence that could indicate that regressions function as a helper for low skilled readers only when it combines with other variables. In this specific case, regressions could be effective because LCR group had more familiarity reading narrative texts and answering textual questions retrieving the explicit information available on the text.

Barnes and Kim (2016) assessed the RC of statements and eye-tracking patterns of children of elementary school and adults with low reading skills, finding no differences between groups. Authors expected better performance for adults because of their oral language development, but they showed short saccades and similar regressions frequency as children. Concerning those results, the function of the regressions frequency was not clear, because it could be a rereading strategy to verify comprehension or a sign of poorer comprehension. However, there 
were found that other eye-tracking parameters could be related to $\mathrm{RC}$, like the total viewing time during regressions, instead of regressions frequency or gaze duration in a word.

Using another methodology for RC assessment, Krstić et al. (2018) found that regressions of low-skilled readers during reading of paragraphs were more variable in frequency, trajectory and length than good readers. Readers who had high-reading-skills used regressions to find specific information to answer textual or inferential questions. On the other hand, low-skilled readers made unorganized saccades to different parts of the text, some of them with few tries and some other with many, most of the time without success.

In summary, there are distinct parameters of regressions useful for the analysis of RC, but the profiles of the readers must be taken into account. Regressions are used for rereading information that readers have missed, forgotten, or are unsure about (Booth \& Weger, 2013). Nevertheless, functions of a regression are not the same in high or low-skilled readers and patterns of regressions change in relation of the reader profile (Krstić et al., 2018). Hence, one of the limitations of this study was that only used regressions frequency in the analysis of RC, parameter insufficient for the assessment of functions of regressions.

Ultimately, contrary to what was expected, participants from both groups, LRC and MRC, showed a higher RC level in inferential questions than in textual questions. Theoretically it has been assumed that answering inferential questions is more complex than answering literal questions (León, Escudero, \& Olmos, 2012; OECD, 2001), and empirically it has been found that elementary, middle and high school students are more likely to answer literal questions than inferential questions (INNE, 2017; OECD, 2015). A possible explanation of this counterintuitive fact is that both groups were low-skilled readers and used the inferences to improve their RC instead retrieving key information using regressions. Regrettably the eye-tracking assessment in this study was limited to regressions frequency, perhaps whether the trajectory, fixation time and length of regressions were measured the explanation would had been answered. It is discussed the necessity of new research to increase the knowledge of RC using eye-tracking parameters.

\section{Acknowledgements}

Authors thank to The Mexican Secretariat of Public Education (SEP) for supporting the research presented in this article through the grants: "Support for the Strengthening of Academic Groups 2017" (Apoyo al Fortalecimiento de Cuerpos Académicos 2017), granted to the CA-UDG-887, and "Support for the Incorporation of Full-time Professors" (Apoyo a la Incorporación de Profesores de Tiempo Completo/F-PROMEP-38/Rev-04, SEP-23-005), granted to Dra. Alicia Abundis Gutiérrez.

\section{Conflicts of Interest}

The authors declare no conflicts of interest regarding the publication of this paper. 


\section{References}

Adams, R., \& Wu, M. (Eds.) (2003). Programme for International Student Assessment (PISA): PISA 2000 Technical Report. París: OECD Publishing. https://doi.org/10.1787/9789264199521-en

Backoff, E. (2009). El aprendizaje en tercero de secundaria en México. México: INEE

Barnes, A. E., \& Kim, Y.-S. (2016). Low-Skilled Adult Readers Look Like Typically Developing Child Readers: A Comparison of Reading Skills and Eye Movement Behavior. Reading and Writing, 29, 1889-1914. https://doi.org/10.1007/s11145-016-9657-5

Best, R., Floyd, R., \& Mcnamara, D. (2008). Differential Competencies Contributing to Children's Comprehension of Narrative and Expository Texts. Reading Psychology, 29, 137-164. https://doi.org/10.1080/02702710801963951

Booth, R. W., \& Weger, U. W. (2013). The Function of Regressions in Reading: Backward Eye Movements Allow Rereading. Memory \& Cognition, 41, 82-97. https://doi.org/10.3758/s13421-012-0244-y

Canales, R. (2012). Asociación entre factores neuropsicológicos, procesos cognitivos y niveles de lectura en niños de diferente nivel socioeconómico del Callao. Revista de Investigación en Psicología, 16, 89-103. https://doi.org/10.15381/rinvp.v16i2.6548

Canales, R., Velarde, E., Meléndez, M., \& Lingán, S. (2014). Lenguaje oral y habilidades lectoras en niños de 4 a 6 años. Un estudio sobre marginalidad y bilingüismo en el Perú. Revista de Investigación en Psicología, 17, 107-119.

https://doi.org/10.15381/rinvp.v17i1.8974

Fuentes, L. (2009). Diagnóstico de comprensión lectora en educación básica en Villarrica y Loncoche, Chile. Perfiles Educativos, 31, 23-37.

González-Becerra, V., García, R., Almeida, M., Navarro, M., Molina, J., \& Ramos, C. (2015). Diferencias de comprensión lectora en estudiantes de 4to y 5to grado de educación primaria de dos municipios de la región de los Valles del estado de Jalisco, México. Revista de Investigación en Psicología, 18, 101-113.

https://doi.org/10.15381/rinvp.v18i2.12086

Hyönä, J., \& Olson, R. K. (1995). Eye Fixation Patterns among Dyslexic and Normal Readers: Effects of Word Length and Word Frequency. Journal of Experimental Psychology: Learning Memory and Cognition, 21, 1430-1440.

https://doi.org/10.1037/0278-7393.21.6.1430

INEE (2016). México en PISA 2015. México: INEE.

INEE (2017). Informe de Resultados Planea 2015: El aprendizaje de los alumnos de sexto de primaria y tercero de secundaria en México. Lenguaje y Comunicación y Matemáticas. México: INEE.

Inhoff, A. W., Weger, U. W., \& Radach, R. (2005). Sources of Information for the Programming of Short- and Long-Range Regressions during Reading. In G. Underwood (Ed.), Cognitive Processes in Eye Guidance (pp. 33-52). Oxford: Oxford University Press. https://doi.org/10.1093/acprof:oso/9780198566816.003.0002

Kintsch, W., \& van Dijk, T. (1978). Toward a Model of Text Comprehension and Production. Psychological Review, 85, 363-394. https://doi.org/10.1037/0033-295X.85.5.363

Koornneef, A., \& Mulders, I. (2017). Can We "Read" the Eye-Movement Patterns of Readers? Unraveling the Relationship between Reading Profiles and Processing Strategies. Journal of Psycholinguistic Research, 46, 39-56.

https://doi.org/10.1007/s10936-016-9418-2

Krstić, K., Šoškić, A., Ković, V., \& Holmqvist, K. (2018). All Good Readers Are the Same, but Every Low-Skilled Reader Is Different: An Eye-Tracking Study Using PISA Data. 
European Journal of Psychology of Education, 33, 521-541. https://doi.org/10.1007/s10212-018-0382-0

León, J., Escudero, I., \& Olmos, R. (2012). Manual de Evaluación de la Comprensión Lectora-ECOMPLEC. Madrid: TEA Ediciones.

Narro, J., \& Moctezuma, D. (2012). Analfabetismo en México: Una deuda pendiente. Realidad. Datos y Espacio: Revista Internacional de Estadística y Geografía, 3, 5-17.

OECD (2001). Knowledge and Skills for Life: First Results from the OECD Programme for International Student Assessment (PISA) 2000. Paris: OECD Publications. https://doi.org/10.1787/9789264195905-en

OECD (2015). PISA 2015 Results in Focus. OECD Publishing. https://www.oecd.org/pisa/pisa-2015-results-in-focus.pdf

Rayner, K. (1990). Comprehension Processes in Reading. Nueva Jersey: Lawrence Earlbaum Associates, Inc.

Rayner, K. (1993). Eye Movements in Reading: Recent Developments. Current Directions in Psychological Science, 2, 81-85. https://doi.org/10.1111/1467-8721.ep10770940

Ribes, E., Ibáñez, C., \& Pérez, R. (2014). Una propuesta metodológica para el análisis experimental del aprendizaje comprensivo. Revista Mexicana de Psicología, 31, 100-110.

Sáenz, L., \& Fuchs, L. (2002). Examining the Reading Difficulty of Secondary Students with Learning Disabilities. Remedial and Special Education, 23, 31-41. https://doi.org/10.1177/074193250202300105

UNESCO (2005). Education for All: Literacy for life. Paris: UNESCO Publishing.

Vorstius, C., Radach, R., \& Lonigan, C. J. (2014). Eye Movements in Developing Readers: A Comparison of Silent and Oral Sentence Reading. Visual Cognition, 22, 458-485. https://doi.org/10.1080/13506285.2014.881445 